\title{
Research on the Rapid Closing Jet Mechanism of Pistol Shrimp's Claws Based on Fluid Dynamic Grid
}

\author{
Wei Wei $\mathbb{D}^{1},{ }^{1}$ Xinyu Quan $\mathbb{D D}^{1}{ }^{1}$ Hongchao Cao ${ }^{D},{ }^{2}$ Shijie Zhang $\mathbb{D}^{1}{ }^{1}$ Ximing Zhao $\mathbb{D},{ }^{1}$ \\ Nan Yu $\mathbb{D}^{1}{ }^{1}$ Jie Zhou $\mathbb{D}^{1},{ }^{1}$ Hongxiang Wang $\mathbb{D}^{1},{ }^{1}$ and Xuyan Hou $\mathbb{D}^{1}$ \\ ${ }^{1}$ State Key Laboratory of Robotics and System, Harbin Institute of Technology, No. 2 Yikuang Street, Nangang, Harbin 150080, \\ Heilongjiang, China \\ ${ }^{2}$ Beihang University, School of Mechanical Engineering \& Automation, Institute of Bionano \& Micronano System, \\ Xueyuan Rd 37, Beijing 100191, China
}

Correspondence should be addressed to Xuyan Hou; houxuyan@hit.edu.cn

Received 23 March 2021; Revised 25 April 2021; Accepted 6 May 2021; Published 15 May 2021

Academic Editor: Zhengbiao Peng

Copyright $\odot 2021$ Wei Wei et al. This is an open access article distributed under the Creative Commons Attribution License, which permits unrestricted use, distribution, and reproduction in any medium, provided the original work is properly cited.

\begin{abstract}
The predation behavior of the pistol shrimp is extremely special, and the predation process will produce a huge popping sound, which has caused extensive research by scholars from all over the world. This article carried out a study on the rapid closing jet mechanism of pistol shrimp's claws. A theoretical model, based on the hydrodynamic characteristics of seawater and the theory of fluid-structure coupling, was proposed for the interaction between the claws and seawater. A simulation model was established using the finite volume software Fluent, and the rapid closing jet mechanism of pistol shrimp's claws was verified by using fluid dynamic grid. This article studied the influence of different fluid models on the simulation results. The effects of the claws' closing angular velocity and angular acceleration on the interaction between the claws and seawater were analyzed, which provides a theoretical basis for the development of new underwater kinetic energy weapons.
\end{abstract}

\section{Introduction}

With the continuous development of science and technology, from shabby wooden fishing boats to battleships with iron bones, from aircraft carrier above water to submarine torpedoes under water, and now many new underwater equipment, the origin of human, the sea, is more and more important. The predation behavior of the pistol shrimp is extremely special, and the predation process will produce a huge popping sound, which has caused extensive research by scholars from all over the world [1-12]. This article carried out a study on the rapid closing jet mechanism of pistol shrimp's claws. The current research on the pistol shrimp mainly focuses on the following aspects: on the one hand, it focuses on the body structure and evolution process of the pistol shrimp, as well as the basic biological characteristics and living habits [13-16]; on the other hand, it focuses on the shooting of the pistol through the high-speed camera system. The jetting behavior of shrimp's claws and the accompanying phenomena of pistol shrimp and goby were studied in detail $[2,7,11,12]$. Another part focuses on the study of the morphological and physiological characteristics of the claws and muscle distribution of the claws $[17,18]$; a few scholars studied the evolution process of the claws in detail [9], including the claws joints' structural differences and evolutionary process [19], and the changes in exercise performance caused by the evolution of the structure of the claws' joints [20]. The existing problems in the current research are as follows: due to the limitations of the experiment, the flow field has not been analyzed in previous studies. Especially when it comes to the investigation of actual pistol shrimps, there are certain limitations in shrimp handling, experimental environment, and conditions, which inherently limits the applicable measurement technology. High-speed photography becomes difficult to perform because it requires a high frame rate (of the order of $106 \mathrm{fps}$ ); lighting and focusing are difficult (animals may move in a less controllable way). The pressure signal recorded by the 
hydrophone may be oversmoothed or underestimated by the bandwidth of the sensor. In addition, the complexity geometry of shrimps' claws and the uniqueness of each individual animal hinder systematic and reproducible research. On the other hand, the experimentally replicated claws lack the conditions for cavitation formation; for cavitation to occur, a high-speed moving object (plunger) is required. This kind of plunger is difficult to realize in actual size, and it is difficult to move at the actual closing speed, and the difficulty in experimental technology makes the research results not accurate enough. Existing research methods focus on experimental research, while fluid-structure coupling simulation can improve the efficiency of verification and reduce costs. The fluid-structure coupling simulation of the rapid closing jet mechanism of pistol shrimps' claws can reduce the limitation of the measurement technology by the uncontrollable movement of live shrimp and it is conducive to systematic and reproducible research. Refer to the reference using CFD method to solve practical engineering problems [21, 22] and the reference on the application of dynamic grid technology in actual engineering problems [23]; based on the cavitation theory and fluid-structure coupling theory, this paper uses the finite volume method software Fluent to construct a model about the seawater contact with the claws and a seawater cavitation model. Carry out a simulation of the claw closure under different working conditions. The effects of different closing angular velocity and different closing angular acceleration on the rapid closing of the claws are analyzed, which provides important support for the study of the rapid closing jet mechanism of pistol shrimps' claws.

\section{Materials and Methods}

2.1. Physical Model. The body of a pistol shrimp is $6 \sim 10 \mathrm{~cm}$ long, with a large claw and a small claw. The large claw is composed of dactylus and pollex. The specific structure is shown in Figure 1. This paper mainly studies the movement of the dactylus of the large claw, so only the model of the large claws needs to be established. At the same time, because the three-dimensional shape of the claws is complicated and difficult to achieve through modeling, only the two-dimensional section of the flow channel is intercepted for modeling. The two-dimensional cross-sectional view of the flow channel and the outline of the large claw are shown in Figures 2(a) and 2(b). MATLAB is used to obtain the boundary contour coordinates of the large claw, and then import to CAD modeling and finally use the model shown in Figure 2(c).

2.2. Hydrodynamic Modeling. The continuity equation for viscous fluid is

$$
\frac{D \rho}{D t}+\rho \nabla \cdot v=\frac{\partial \rho}{\partial t}+\nabla(\rho v)=0
$$

The N-S equation of incompressible viscous fluid is

$$
\frac{D v}{D t}=\frac{\partial v}{\partial t}+(v \cdot \nabla) v=f-\frac{1}{p}+v \nabla^{2} v .
$$

When the partial pressure of a place in the flow field is lower than the saturated vapor pressure at that place, not only the air dissolved in the water (usually $2 \%$ ) will escape, but also the water will start to vaporize, forming a lot of cavitation bubbles composed of air and steam in the water. These cavitation bubbles are carried by the water flow and collapse when they reach the high-pressure zone. The whole process of the initiation, growth, and collapse of the cavitation bubbles is called cavitation. The degree of cavitation is usually expressed by the dimensionless cavitation index $\sigma$, which is defined as

$$
\sigma=2 \frac{P_{0}-P_{v}}{\rho V_{0}^{2}},
$$

where $P_{0}$ is the environmental pressure, $V_{0}$ is the exit speed, $P_{v}$ is the saturated vapor pressure of water, and $\rho$ is the density of water.

The cavitation number $\sigma$ can be considered as the ratio between the force that inhibits cavitation and the force that promotes cavitation, and it represents whether cavitation appears and the degree of cavitation in the flow field. If the cavitation number when cavitation occurs in water is defined as the initial cavitation number $\sigma_{i}$, when the cavitation number of the flow field $\sigma>\sigma_{i}$, no cavitation occurs; when $\sigma=\sigma_{i}$, it is in the critical state of cavitation; when $\sigma<\sigma_{i}$, cavitation will occur, and the cavitation area will be enlarged as the cavitation number $\sigma$ decreases. When $\sigma<1$, it is considered that cavitation has occurred, and when $\sigma<0.5$, it is considered that stable cavitation has occurred.

For an isolated spherical bubble in a static state in the water, it is assumed that the bubble contains only water vapor. In the case of ignoring the gas diffusion in water, the balance condition of the bubble is

$$
p=P_{v}-\frac{2 S}{R}
$$

where $p$ is the water pressure on the wall around the bubble, $S$ is the surface tension coefficient of water, and $R$ is the spherical bubble radius.

In fact, in addition to water vapor in the general bubble, there are some gases originally dissolved in water, which diffuse from the surrounding water into the bubble. At this situation, the static balance equation can be written as

$$
p=P_{v}+P_{g}-\frac{2 S}{R}
$$

where $P_{g}$ is the partial pressure of gas in bubble.

If $P_{v}$ is considered to be a constant, and because the specific heat capacity of the surrounding water is large, the gas mass is very small, and the heat imbalance caused by the diffusion of gas from the water into the bubble will soon be adjusted by the surrounding water. In this way, the temperature of vapor and gas in the bubble can be considered constant. When the change process of $R$ is very fast, it is 


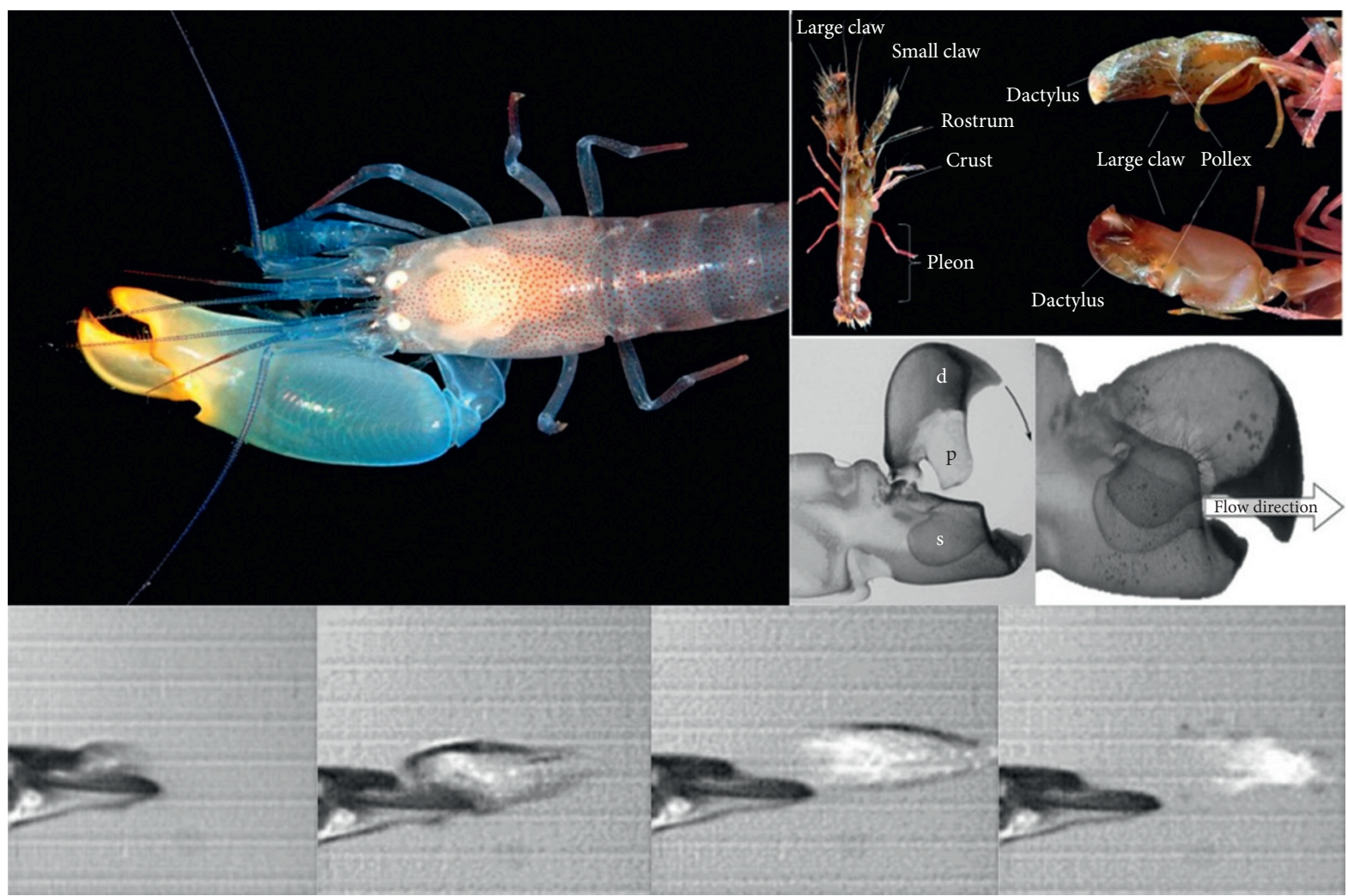

FIgURE 1: Structure of pistol shrimp.

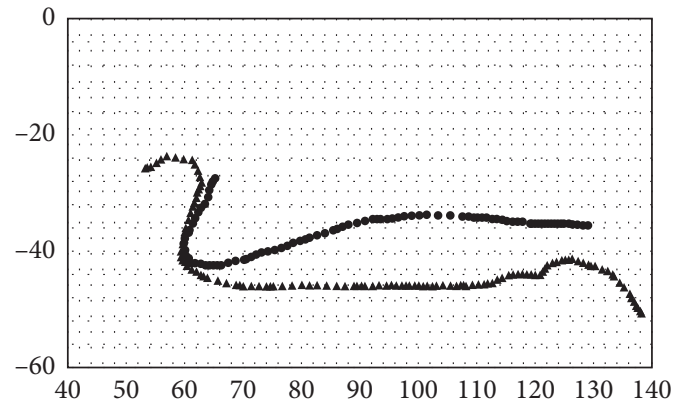

(a)

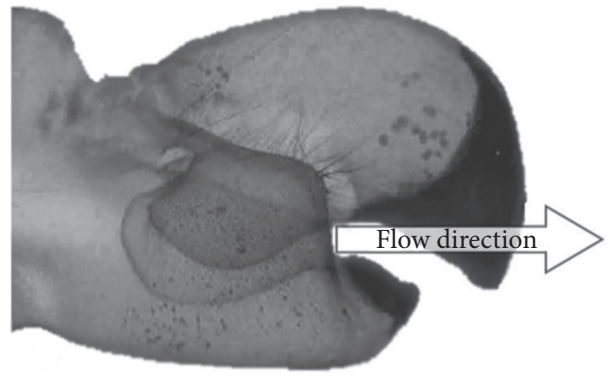

(b)

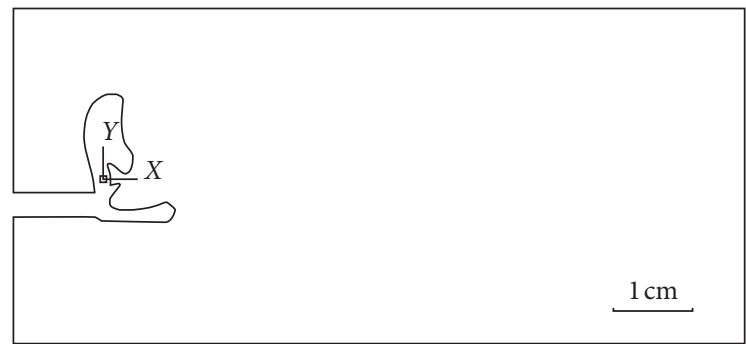

(c)

Figure 2: (a) Two-dimensional cross section of the channel. (b) Shape of pistol shrimp's large claw. (c) Two-dimensional model of pistol shrimp's large claw. 
regarded as an ideal gas adiabatic process, so $P_{g}$ in equation (5) becomes

$$
P_{g}=P_{g 0}\left(\frac{V_{0}}{V}\right)=P_{g 0}\left(\frac{R_{0}}{R}\right)^{3},
$$

where $P_{g 0}, V_{0}$, and $R_{0}$, respectively, are partial pressure of gas, bubble radius, and bubble volume in an initial state and $P_{g}, V$, and $R$, respectively, are partial pressure of gas, bubble radius, and bubble volume in other states.

Substituting equation (6) into (5), the static balance conditions for the adiabatic process of cavitation bubble containing steam and gas can be obtained:

$$
p=P_{v}+\left(P_{0}-P_{v}+\frac{2 S}{R}\right)\left(\frac{R_{0}}{R}\right)^{3}-\frac{2 S}{R} .
$$

The Rayleigh-Plesset (R-P) equation is an ordinary differential equation that simulates the motion of bubbles in a fluid. At present, most of the cavitation numerical models applied to engineering problems are derived from the R-P equation that only considers the first derivative term of the cavitation bubble radius and the pressure-driven term. This type of model does not consider the influence of the second derivative term, viscosity term, and surface tension term on the growth of bubble radius.

The Rayleigh-Plesset (R-P) equation is

$$
\frac{P_{B}-P_{\infty}}{\rho_{L}}=R \ddot{R}+\frac{3}{2} \dot{R}^{2}+\frac{4 \vartheta_{L}}{R} \dot{R}+\frac{2 S}{\rho_{L} R},
$$

where $P_{B}$ is the pressure in the bubble, $P_{\infty}$ is the pressure at infinity from the cavitation bubble, $\rho_{L}$ is the density of surrounding liquid, $R$ is the cavitation bubble radius, $\vartheta_{L}$ is the viscosity of the surrounding liquid, and $S$ is the cavitation surface tension.

The second derivative term in the complete R-P equation has an important influence on the growth of the bubble radius and cannot be ignored [24]. The actual fluid also contains noncondensable gas (NCG). The saturated mass concentration of NCG that can be dissolved by pure water at a standard atmospheric pressure is $1.5 \times 10^{3} \mathrm{mg} / \mathrm{L}$. This part of the gas acts as a cavitation nucleus in the process of cavitation, which plays an important role in the initiation of cavitation [25].

Using multiphase cavitation modeling methods, basic two-phase cavitation models include standard viscous flow equations that use controlled mixture (mixed model) or phase (Eulerian multiphase) transport and conventional turbulence models $(k-\varepsilon$ model). In cavitation, liquid-gas mass transfer (evaporation and condensation) is controlled by the vapor transport equation:

$$
\frac{\partial}{\partial t}\left(\alpha \rho_{v}\right)+\nabla \cdot\left(\alpha \rho_{v} \bar{V}_{v}\right)=R_{e}-R_{c},
$$

where $\alpha$ is the gas volume fraction, $\rho_{v}$ is the gas density, $\bar{V}_{v}$ is the gas velocity, and $R_{e}$ and $R_{c}$ are the mass transfer source terms, which, respectively, are related to the growth and collapse of the vapor bubble.

In formula (9), $R_{e}$ and $R_{c}$ represent the mass transfer between liquid and gas phases in cavitation. They are based on the Rayleigh-Plesset equation of formula (8), which describes the growth of a single vapor bubble in the liquid. The equation for the vapor volume fraction from equation (9) has a general form:

$$
\frac{\partial}{\partial t}\left(\alpha \rho_{v}\right)+\nabla \cdot\left(\alpha \rho_{v} \bar{V}_{v}\right)=\frac{\rho_{v} \rho_{l}}{\rho} \frac{D \alpha}{D t} .
$$

The sources of net quality are as follows:

$$
R=\frac{\rho_{v} \rho_{l}}{\rho} \frac{\mathrm{d} \alpha}{\mathrm{d} t}
$$

The vapor volume fraction is related to the number of bubbles per volume of liquid to get the following equation:

$$
\alpha=\frac{n_{b}(4 / 3) \pi R_{B}^{3}}{1+n_{b}(4 / 3) p R_{B}^{3}},
$$

where $n_{b}$ is the bubble number density.

Substitute equations (11) and (12) into equation (10) to derive the following equation:

$$
\begin{aligned}
R & =\frac{\rho_{v} \rho_{l}}{\rho} \alpha(1-\alpha) \frac{3}{R_{B}} \sqrt{\frac{2}{3} \frac{\left(P_{v}-P\right)}{\rho_{l}}} \\
R_{B} & =\left(\frac{\alpha}{1-\alpha} \frac{3}{4 \pi} \frac{1}{n}\right)^{(1 / 3)} .
\end{aligned}
$$

where $R$ is the mass transfer rate and $R_{B}$ is the bubble radius.

The mass transfer rate in the model is proportional to $\alpha_{v}\left(1-\alpha_{v}\right)$. In addition, the value of this function is zero when $\alpha=0$ and $\alpha=1$ and reaches the maximum value between them. Also, in this model, the only parameter that must be determined is the number of bubbles per unit volume of liquid. If it is assumed that no bubbles are generated or destroyed, the bubble number density will remain unchanged.

The final form of the model is as follows:

When $P_{v}>P$,

$$
R_{e}=\frac{\rho_{v} \rho_{l}}{\rho} \alpha(1-\alpha) \frac{3}{R_{B}} \sqrt{\frac{2}{3} \frac{\left(P_{v}-P\right)}{\rho_{l}} .}
$$

When $P_{v} \leq P$,

$$
R_{c}=\frac{\rho_{v} \rho_{l}}{\rho} \alpha(1-\alpha) \frac{3}{R_{B}} \sqrt{\frac{2}{3} \frac{\left(P-P_{v}\right)}{\rho_{l}} .}
$$

There are three existing turbulence numerical simulation methods: direct numerical simulation (DNS), Reynolds average Navier-Stokes (RANS), and large eddy simulation (LES). DNS is currently limited to small scale and small Renumber simulation because it consumes too much computing resources and is difficult to apply in practical engineering. RANS is the application of statistical theory of turbulence, which is the simulation method commonly used in engineering. The unsteady N-S equation is averaged over time, and the Reynolds stress is assumed based on the theoretical knowledge of turbulence, experimental data, or DNS results; that is, various empirical and semiempirical 
constitutive relations are assumed, so that the average Reynolds equation of turbulence is closed. According to the different starting points for model processing, turbulence model theory can be divided into two categories: one type introduces the governing equation of the second-order pulsation term to form a second-order moment closed model called the Reynolds stress model; another is the eddy viscosity closed mode based on Boussinesq's eddy viscosity hypothesis, such as zero-equation model, one-equation model, and two-equation model. Due to the large amount of calculation of the Reynolds stress model, the application occasions are very limited. The eddy viscous closed mode has lower requirements on the computer and at the same time can obtain calculation results that meet engineering requirements.

The zero-equation model has a common shortcoming; that is, the turbulence viscosity coefficient only depends on the local flow parameters and has nothing to do with the flow elsewhere, which is inconsistent with experimental observations. On this basis, one-equation model and two-equation model were developed. Among the two-equation model, the $k-\varepsilon$ model has certain accuracy and consumes limited computing resources, so it has been widely used. This paper compares the effects of three $k$ - $\varepsilon$ models on the experimental results.

2.3. Simulation Model. Use the preprocessing software Gambit to mesh the calculation space. Import the model into Gambit and use a rectangular area five times the length and three times the width of the model as the boundary of the computational domain. The area near the claws needs to be focused, so the density of the grid nodes near the claws should be increased. The height of the first cell perpendicular to the body surface is $0.05 \mathrm{~mm}$. This height is chosen to make $y+$ of most of the cells in contact with the body surface within the effective range of the standard wall function. At the same time, considering the calculation speed, the outer division step of the model is taken as $0.1 \mathrm{~mm}$, the boundary and the movable chelate are set after the compliant grid, and the interior is filled with seawater. The model is shown in Figure 3.

Import the .mesh file exported by Gambit into Fluent, and set the seawater parameters according to the living environment of pistol shrimps, as shown in Table 1. Use Fluent for rapid closing simulation, and set the model boundary parameters as shown in Table 2. After consulting the literature and referring to the official Fluent parameter settings, the simulation parameters are shown in Table 3. The movement of the dactylus is controlled by Fluent UDF.

\section{Results and Discussion}

The interaction process between the claws and seawater is short, so data postprocessing is needed to select appropriate feature quantities to characterize the interaction process and the result. What can be obtained intuitively are the pressure cloud graph, velocity cloud graph, and bubble volume fraction cloud graph during the closing process, which can reflect the cavitation phenomenon in the closing process in a certain extent. The dynamic response curve of seawater is obtained through data postprocessing, which can show the changes of pressure, velocity, and bubble size at a certain point in the process of interaction between the claws and seawater. Through the comparative analysis under different conditions, the influence of different parameters on the closing speed and cavitation effect of the claws can be concluded.

3.1. Simulation Process. Under the condition of closing angular velocity of $3500 \mathrm{rad} / \mathrm{s}$, closing time of $0.5 \mathrm{~ms}$, and closing angle of $90^{\circ}$, the pressure cloud graph, velocity cloud graph, and bubble volume fraction cloud graph are set to monitor, and images of pressure, velocity, and bubble volume change with time are obtained.

It can be seen from Figure 4 that, due to the rapid movement of the dactylus, a low-pressure area is formed at its tip. At the same time, as the claw closes, the seawater speed increases continuously, and the seawater between the dactylus and the pollex is compressed, and the pressure increases to form a jet. The jet velocity reaches $40 \mathrm{~m} / \mathrm{s}$, causing the seawater pressure in front to rapidly decrease below the saturated vapor pressure, and the gas core scattered in the seawater quickly grows into bubbles and moves at high speed in the direction of the jet. At $0.6 \mathrm{~ms}$, the bubbles collapse instantly under the huge pressure of the surrounding seawater, forming huge pressure. The seawater basically returns to normal at $0.7 \mathrm{~ms}$.

It can be seen from Figures 5 and 6 that the claw outlet and bubble formation position are ideal positions to measure the pressure, velocity, and bubble size during the closing process, so mark points 1 and 2 in Figure 7 to analyze the specific numerical changes during the closing process and the law of change.

\subsection{Influence of Turbulence Model on Simulation Accuracy.} Using a closing angular velocity of $7000 \mathrm{rad} / \mathrm{s}$, a closing time of $0.25 \mathrm{~ms}$, and a closing angle of $90^{\circ}$, three sets of simulations were performed by changing the turbulence model. The results are shown in Figure 8, which is the dynamic response curve of seawater pressure under different turbulence models. It can be seen that, under different turbulence models, the morphological characteristics of the dynamic response curve of seawater are consistent. In the closing stage, the pressure changes under the three models are basically the same, and the overall trend is increasing, with the maximum pressure reaching $2 \times 10^{6} \mathrm{~Pa}$. After the cavitation bubbles are produced, the three models appear different. The pressure curve under the Realizable model changes greatly and is unstable, which is manifested by the large difference between the peak and valley values of the pressure. The pressure peak appears earlier under the Standard model, indicating that the bubble bursts earlier.

Figure 9 is the velocity change curve of point 1 and point 2 under different turbulence models. It can be found that the dynamic response curve of seawater has the same morphological characteristics. Within $0 \sim 0.4 \mathrm{~ms}$ after closing, the 


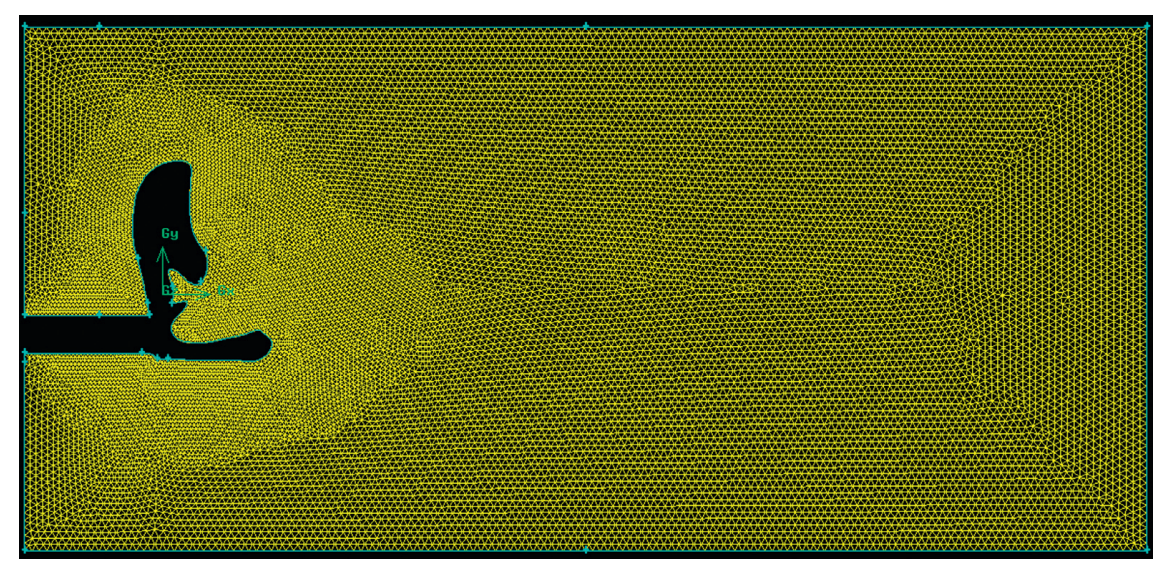

FIGURE 3: Grid chart in Gambit.

TABLE 1: Seawater parameters.

\begin{tabular}{lcc}
\hline Parameter & Model value & Actual value \\
\hline Temperature $\left({ }^{\circ} \mathrm{C}\right)$ & 20 & $18-24$ \\
Salinity & $5 \%$ & $5 \%$ \\
Density $\left(\mathrm{kg} / \mathrm{m}^{3}\right)$ & 1024 & 1024 \\
Dynamic viscosity $(\mathrm{mPa} \mathrm{s})$ & 1.140 & 1.140 \\
Pressure $(\mathrm{Pa})$ & 302820 & $1.5 \sim 6.5 \times 10^{5}$ \\
Saturated vapor pressure $(\mathrm{Pa})$ & 2292 & 2291.66 \\
\hline
\end{tabular}

TABLE 2: Model boundary parameters.

\begin{tabular}{lc}
\hline Boundary name & Boundary type \\
\hline Dactylus & Wall \\
Pollex & Wall \\
Outlet & Pressure outlet $(302820 \mathrm{~Pa})$ \\
Move1 & Deforming \\
Move2 & Deforming \\
Seawater & Interior \\
\hline
\end{tabular}

TABle 3: Preset parameters for CFD simulation.

\begin{tabular}{lc}
\hline Parameter & Preset value \\
\hline Solver & Pressure based \\
Time & Transient \\
Turbulence model & RNG $k-\varepsilon$ model \\
Pressure-velocity coupling & PISO \\
Transient formulation & First-order implicit \\
Other term spatial discretization & First-order upwind \\
Time step size & $1 \times 10^{-6}(\mathrm{~s})$ \\
Number of time steps & 500 \\
\hline
\end{tabular}

velocity changes under the three models are basically consistent; after $0.4 \mathrm{~ms}$, the seawater reverses in the Realizable model and the RNG model, causing the velocity of point 1 to increase again, but the Standard model does not appear. The velocity of point 2 does not obviously change because the location is far from the channel.

Figures 10(a)-10(c) show the images of cavitation bubbles under different turbulence models. The shapes of cavitation bubbles produced under different turbulence models are similar. The bubble vapor volume fraction generated by the RNG model and the Realizable model is larger, and the bubble vapor volume fraction generated by the Standard model is smaller; the bubble size generated by the RNG model and the Standard model is not much different, and the bubble generated by the Realizable model is larger.

The same result can be obtained from Figure 10(d); that is, the size of the bubbles generated by the RNG model and the Standard model is not much different, and the bubbles generated by the Realizable model are larger. Referring to the simulation settings of other scholars, it is shown that the RNG model is more in line with the actual situation of this research $[14,26,27]$.

3.3. Effect of Closing Angular Velocity. In order to obtain the relationship between the closing process and the closing speed, three sets of angular velocity-time are designed as shown in Figure 11. Keep the closing angle unchanged at $90^{\circ}$, the peak closing angular velocities are $1810 \mathrm{rad} / \mathrm{s}$, $3631 \mathrm{rad} / \mathrm{s}$, and $7300 \mathrm{rad} / \mathrm{s}$, and the closing time is $1 \mathrm{~ms}$, $0.5 \mathrm{~ms}$, and $0.25 \mathrm{~ms}$, respectively. Since the rotation direction of the claws is clockwise, the closing angular velocity is negative.

Import the measurement data under different closing speeds into MATLAB to observe the influence of closing angular speed on pressure more intuitively. As shown in Figures 12(a)-12(c), it is the pressure change curve of the dactylus, point 1 , and point 2 under different closing angular velocities. It can be found that the dynamic response curve morphology characteristics of seawater under different closing angular velocities are the same but with different peaks. Since the closing angle has a fixed value of $90^{\circ}$, a large closing speed will result in a short closing time, which represents an earlier response; a small closing speed will result in a long closing time, which represents a lag in response. The small pressure is positively correlated with the speed.

Take the minimum pressure of the dactylus at the jet and the closing angular velocity to perform MATLAB fitting to obtain the relationship between cavitation and the closing angular velocity. The result is shown in Figure 12(d). 


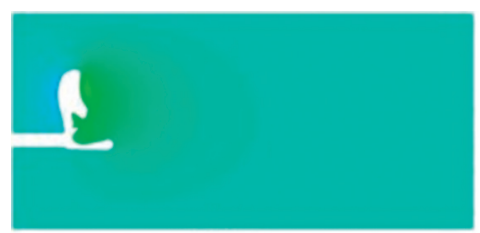

$0.0 \mathrm{~ms}$

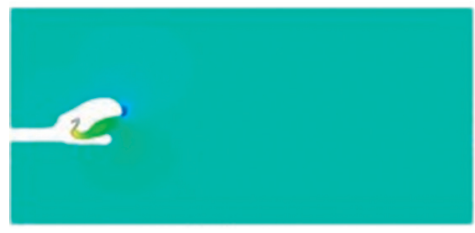

$0.4 \mathrm{~ms}$

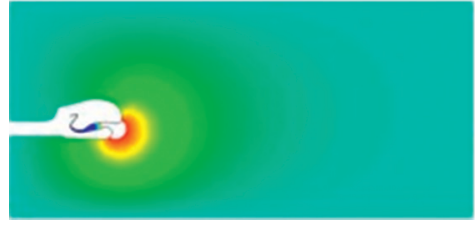

$0.6 \mathrm{~ms}$

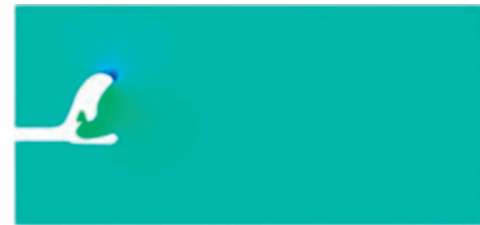

$0.2 \mathrm{~ms}$

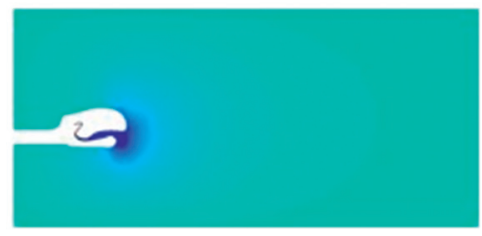

$0.5 \mathrm{~ms}$

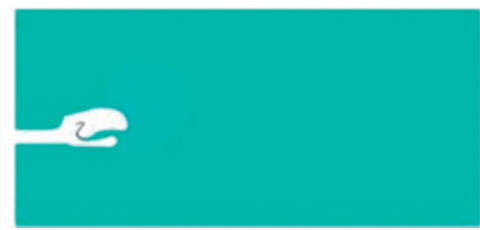

$0.7 \mathrm{~ms}$

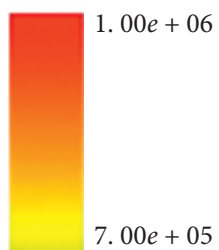

3. $00 e+05$

FIGURE 4: Changes in pressure of seawater during claw closing.
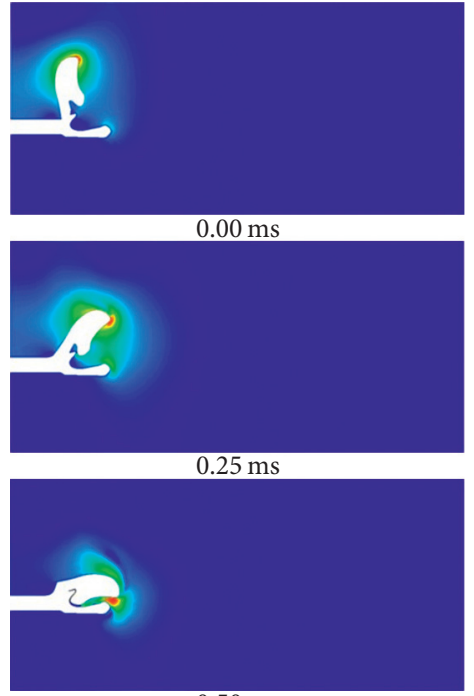

$0.50 \mathrm{~ms}$

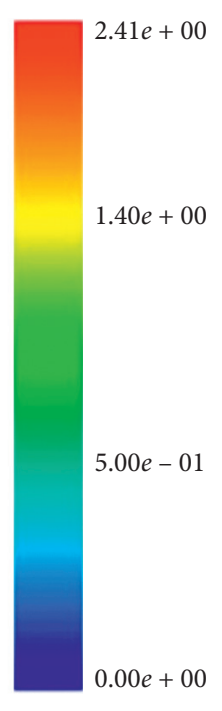

Figure 5: Changes in velocity of seawater during claw closing.

Fitting with exponential function, the fitting results are as follows:

$$
\begin{aligned}
& P=a x^{b}, \\
& a=4.147 \times 10^{26}, \\
& b=-6.548 .
\end{aligned}
$$

The fitting result is good, and the saturated vapor pressure under the model is substituted into the function to obtain the critical closing angular velocity as $\omega_{z}=2466.6 \mathrm{rad} / \mathrm{s}$.

Figures 13(a)and 13(b) show the velocity curves of point 1 and point 2 with time under different closing speeds. It can be found that the velocity curve has the same change trend with the pressure curve. The curve shape characteristics are the same, and the peak values are different. The velocity at point 1 and point 2 is positively correlated with the closing velocity.

In order to summarize the relationship between closure velocity and cavitation, the peak velocity and angular velocity peak at point 1 are imported into MATLAB for fitting. The fitting expression is

$$
\begin{aligned}
& V=p_{1} x^{2}+p_{2} x+p_{3}, \\
& p_{1}=3.713 \times 10^{-6}, \\
& p_{2}=-0.009242, \\
& p_{3}=24.61 .
\end{aligned}
$$

The drawn image is shown in Figure 13(c), and the fitting result is good. It is known from equation (3) that when the jet velocity $V_{0}=24.22 \mathrm{~m} / \mathrm{s}$, cavitation occurs; when $V_{0}=34.26 \mathrm{~m} / \mathrm{s}$, stable cavitation occurs. Substituting $V_{0}=$ $24.22 \mathrm{~m} / \mathrm{s}$ into equation (17), the critical closing angular velocity for cavitation is $2446.8 \mathrm{rad} / \mathrm{s}$, which is basically the same as the result obtained from equation (19).

Figure 14 is the volume image of cavitation bubbles formed at different closing angular velocities, and Figure 15(a) is the bubble volume fraction curve at different closing angular velocities. The image shows that when the closing angular velocity is small, the velocity of the water jet is small, and the pressure drop cannot meet the requirements of cavitation, so cavitation bubbles cannot be generated. When the angular velocity is large, the velocity of the water jet increases, causing the pressure to drop below the saturated vapor pressure, so the generated cavitation bubbles are larger. The proportion of bubbles is positively correlated with the closing angular velocity, but as the closing speed increases, the growth rate of the proportion of bubbles slows down. 


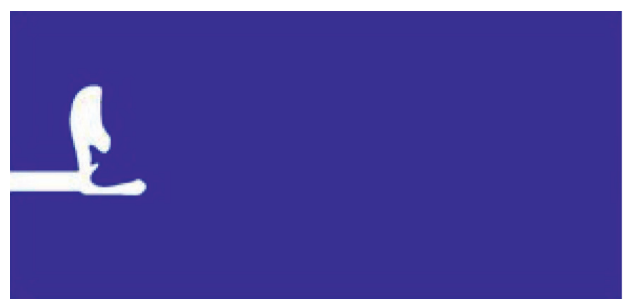

$0.00 \mathrm{~ms}$

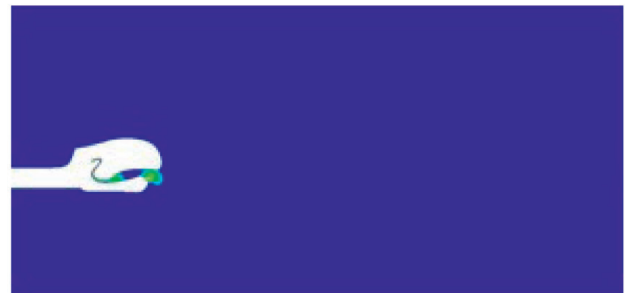

$0.50 \mathrm{~ms}$

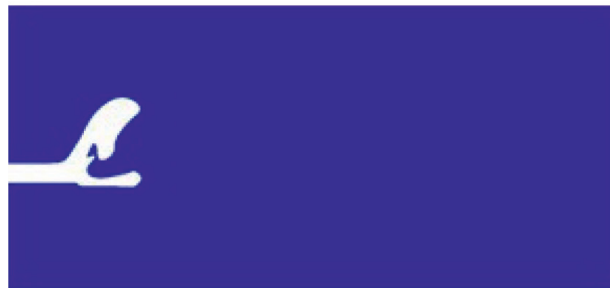

$0.25 \mathrm{~ms}$

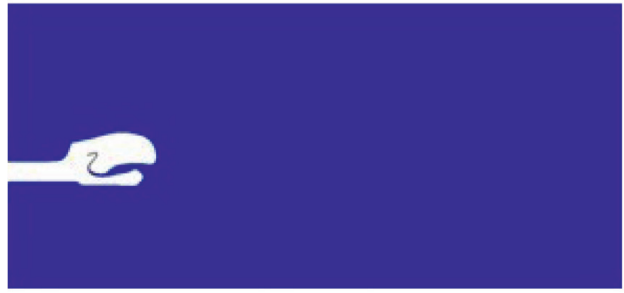

$0.70 \mathrm{~ms}$

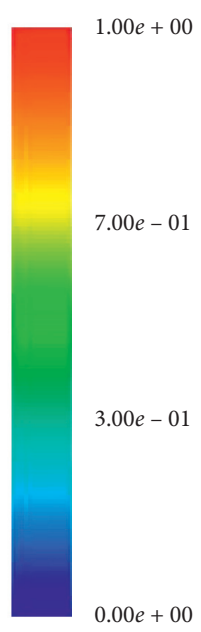

$0.00 e+00$

FIGURE 6: Changes in bubble volume during claw closing.

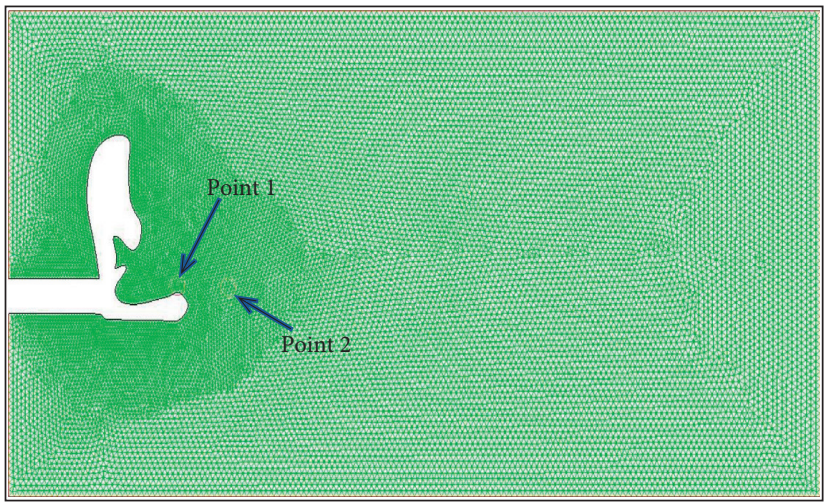

Figure 7: Position of point 1 and point 2.
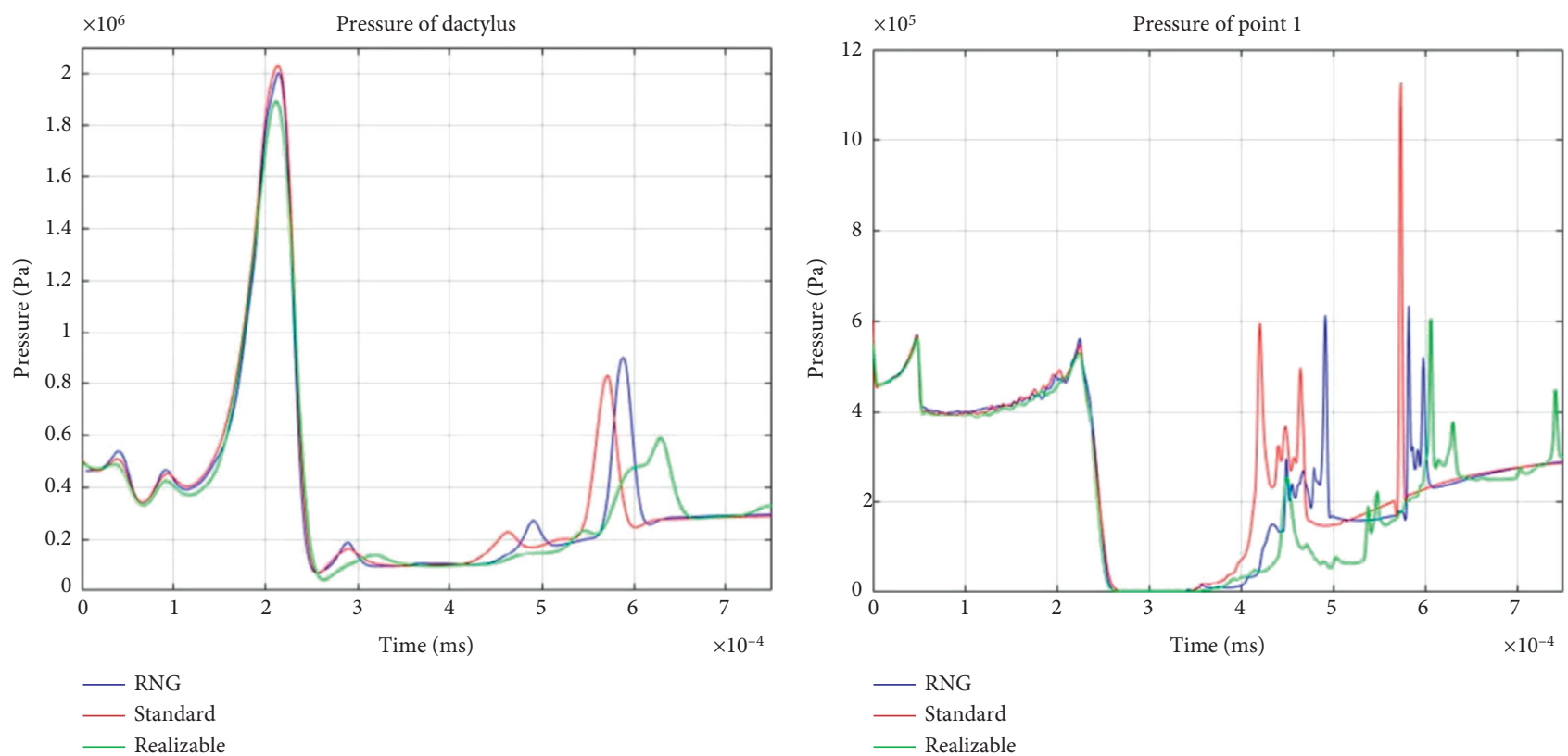

(a)

(b)

Figure 8: Continued. 


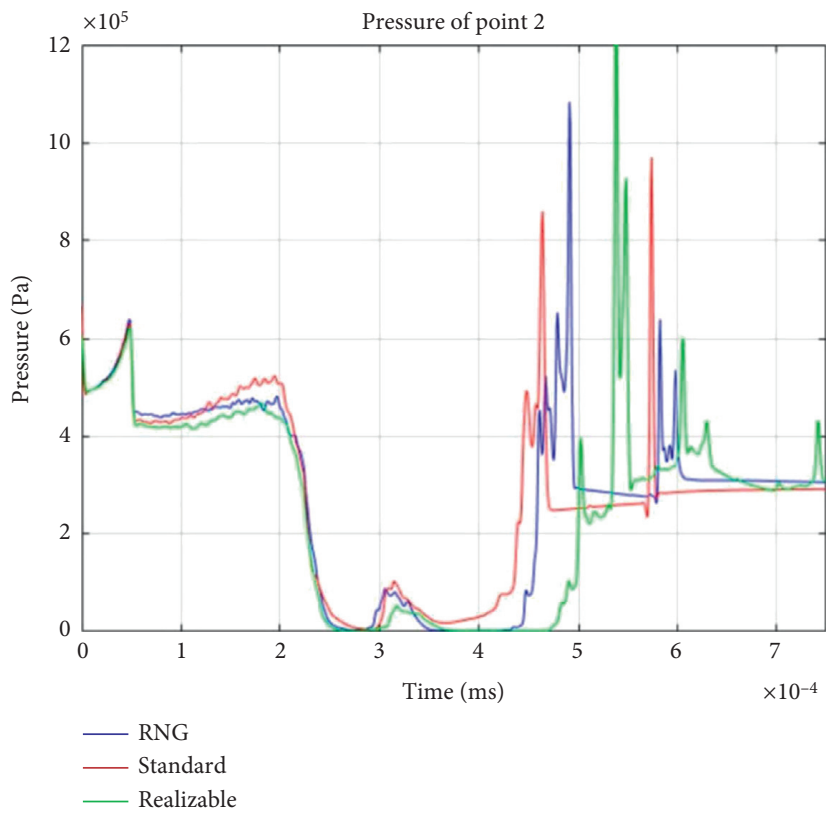

(c)

Figure 8: Pressure curves under different turbulence models. (a) Pressure of dactylus. (b) Pressure of point 1. (c) Pressure of point 2.

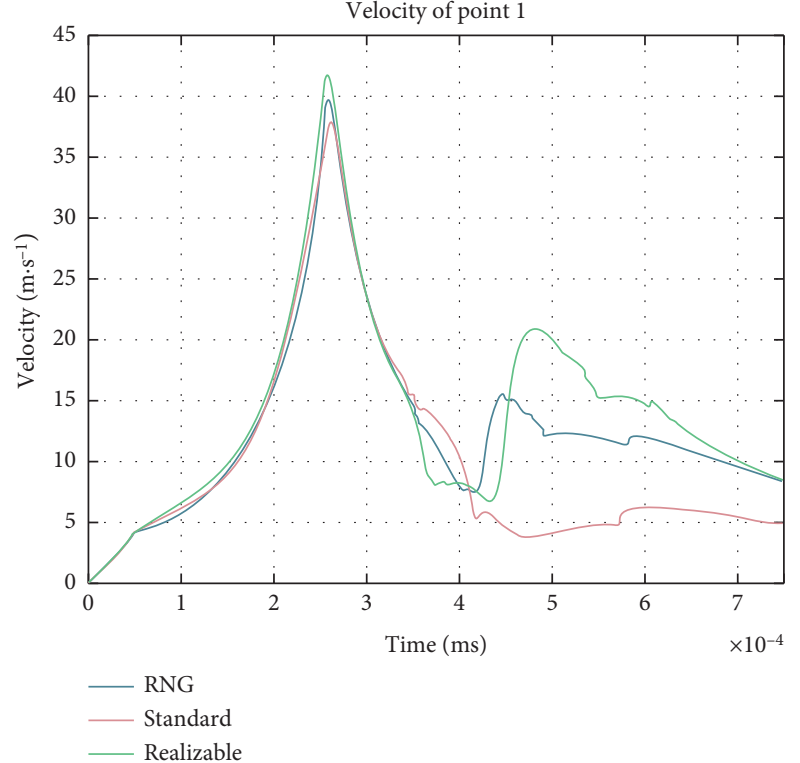

(a)

FIgURE 9: Velocity curves under different turbulence models.

From equations (16) and (17), the critical closing angular velocity is $2456 \mathrm{rad} / \mathrm{s}$, and the bubble size and movement distance can be set to zero at this time. The bubble is ellipsoidal at $3631 \mathrm{rad} / \mathrm{s}$, and, at $7300 \mathrm{rad} / \mathrm{s}$ due to the closing angular velocity being too high, the bubble deforms into an irregular shape. Observe that the sizes of the bubble at $3631 \mathrm{rad} / \mathrm{s}$ and $7300 \mathrm{rad} / \mathrm{s}$ in Figure 13 are $4 \mathrm{~mm}$ and $12 \mathrm{~mm}$, respectively, and the bubble movement distance is $6 \mathrm{~mm}$ and $10 \mathrm{~mm}$, respectively. The bubble size and closing angular velocity image can be obtained as shown in Figure 15(b), and the fitting result is

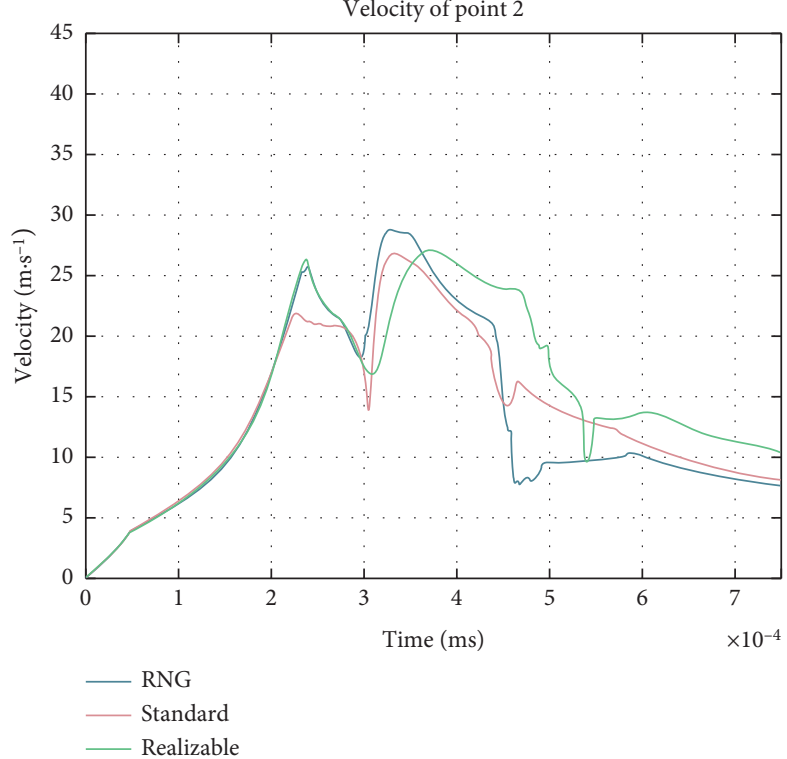

(b)

(a) Velocity curves of point 1. (b) Velocity curves of point 2.

$$
\begin{aligned}
d & =p_{1} x^{2}+p_{2} x+p_{3}, \\
p_{1} & =-2.526 \times 10^{-7}, \\
p_{2} & =0.004942, \\
p_{3} & =-10.61 .
\end{aligned}
$$

The image of bubble movement distance and closing angular velocity is shown in Figure 15(c) and the fitting result is 


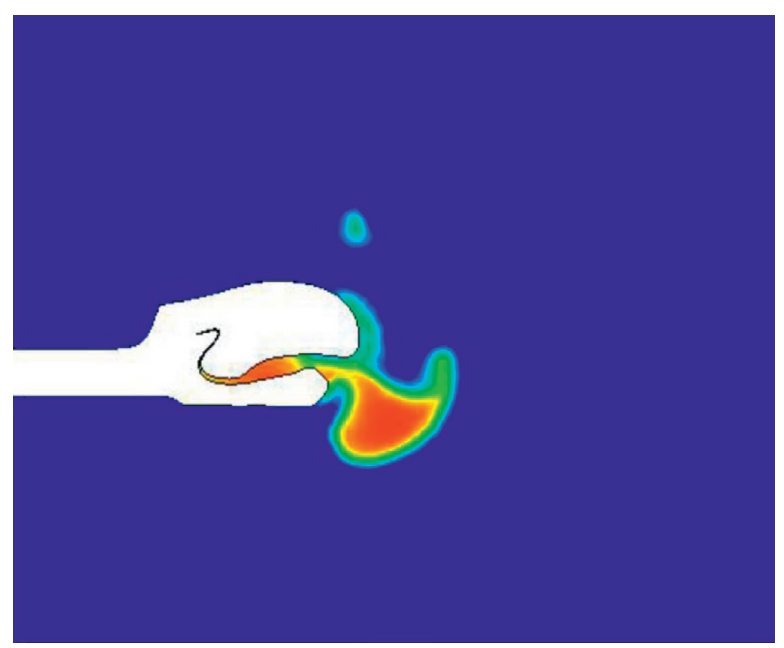

(a)

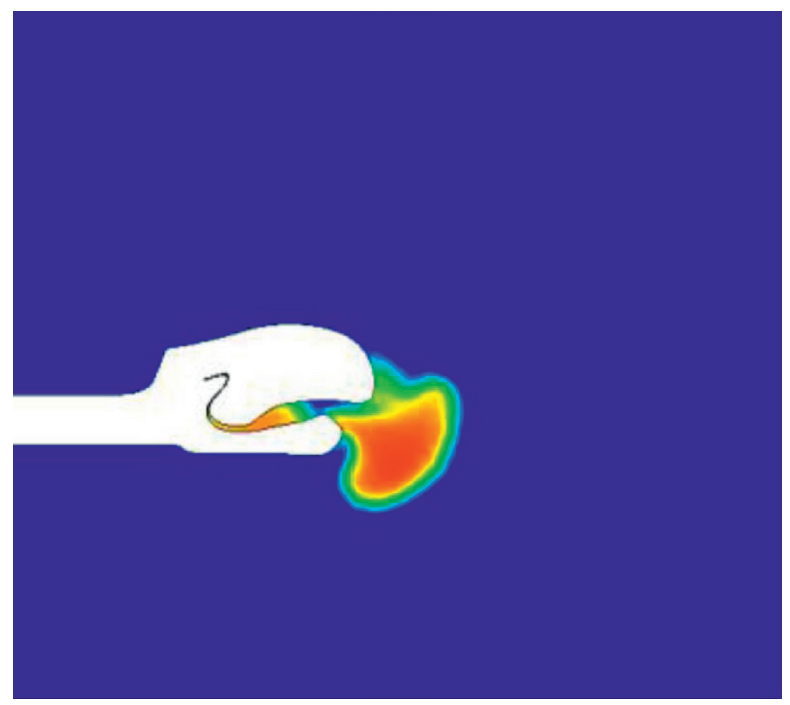

(c)

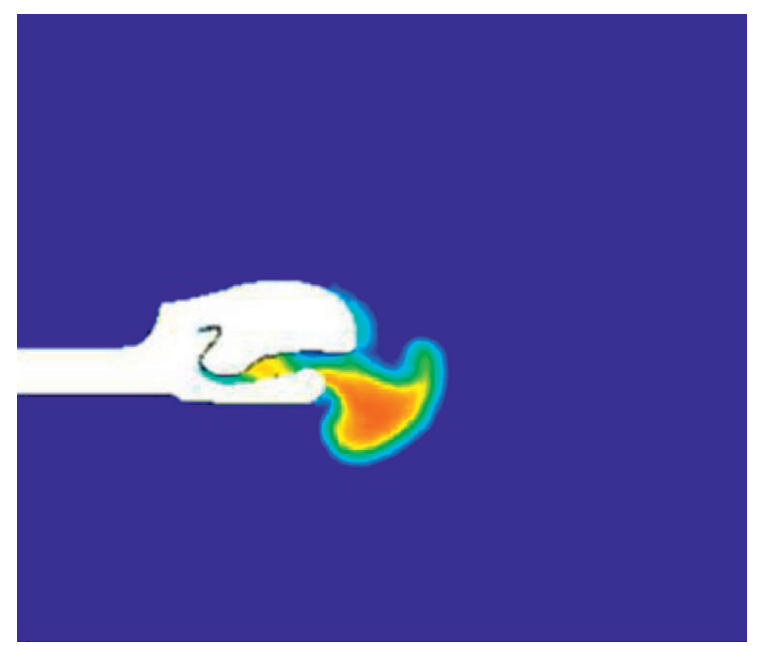

(b)

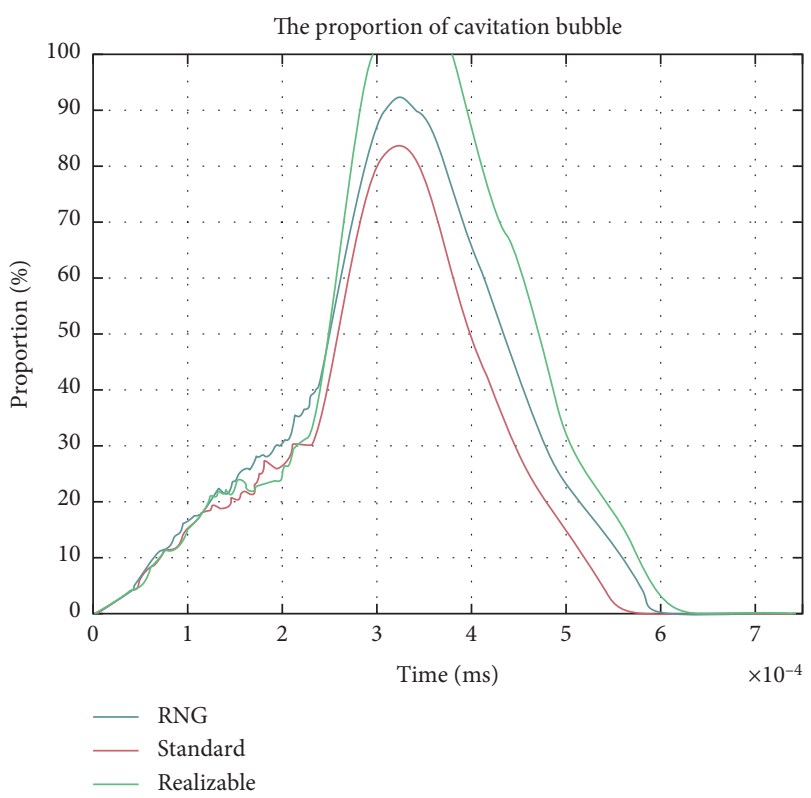

(d)

FIgURE 10: The proportion of cavitation bubble under different turbulence models. (a) RNG models. (b) Standard models. (c) Realizable models. (d) The proportion of cavitation bubble curves under different turbulence models.

$$
\begin{aligned}
d_{2} & =a x^{b}+c \\
a & =-3.168 \times 10^{7} \\
b & =-1.9 \\
c & =11.44 .
\end{aligned}
$$

3.4. Effect of Closing Angular Acceleration. When studying the effect of the closing angular acceleration on the interaction between the claws and seawater, the maximum angular velocity is kept unchanged at $\omega_{\max }=4000 \mathrm{rad} / \mathrm{s}$, the closing angle remains unchanged at $90^{\circ}$, and the angular acceleration is $\alpha_{1}=0.75 \times 10^{7} \mathrm{rad} / \mathrm{s}^{2}, \alpha_{2}=1 \times 10^{7} \mathrm{rad} / \mathrm{s}^{2}$, and $\alpha_{3}=1.5 \times 10^{7} \mathrm{rad} / \mathrm{s}^{2}$; the angular velocity-time image is shown in Figure 16. Since the rotation direction of the claws is clockwise, the closing angular acceleration is negative.
Import the measurement data at different closing speeds into MATLAB to observe the effect of closing angular acceleration on pressure more intuitively. Figure 17 is the pressure change curve of the dactylus, point 1 , and point 2 under different closing angular accelerations. It can be found that the dynamic response curve of seawater has the same shape characteristics and different peak values under different closing angular accelerations. Since the closing angle is a fixed value of $90^{\circ}$, the closing time under $\alpha_{2}=1 \times 10^{7} \mathrm{rad} / \mathrm{s}^{2}$ is exactly $0.5 \mathrm{~ms}$, and the closing angular acceleration under $\alpha_{3}=1.5 \times$ $10^{7} \mathrm{rad} / \mathrm{s}^{2}$ is relatively larger, so the closing time is short, and the response is earlier; when the closing angular acceleration is smaller under $\alpha_{1}=0.75 \times 10^{7} \mathrm{rad} / \mathrm{s}^{2}$, the closing time is longer, and the response lags. The peaks of pressure are not much different, and they increase slightly with the increase of angular acceleration; the valleys of pressure are exactly the same. 


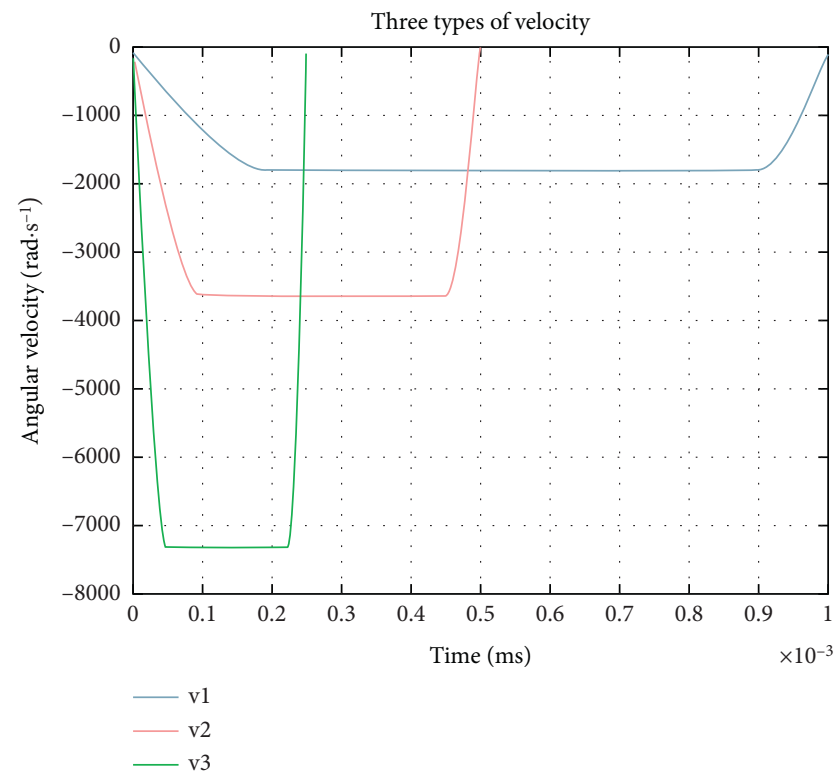

Figure 11: Three types of closing angular velocity of the pistol shrimp's claw.
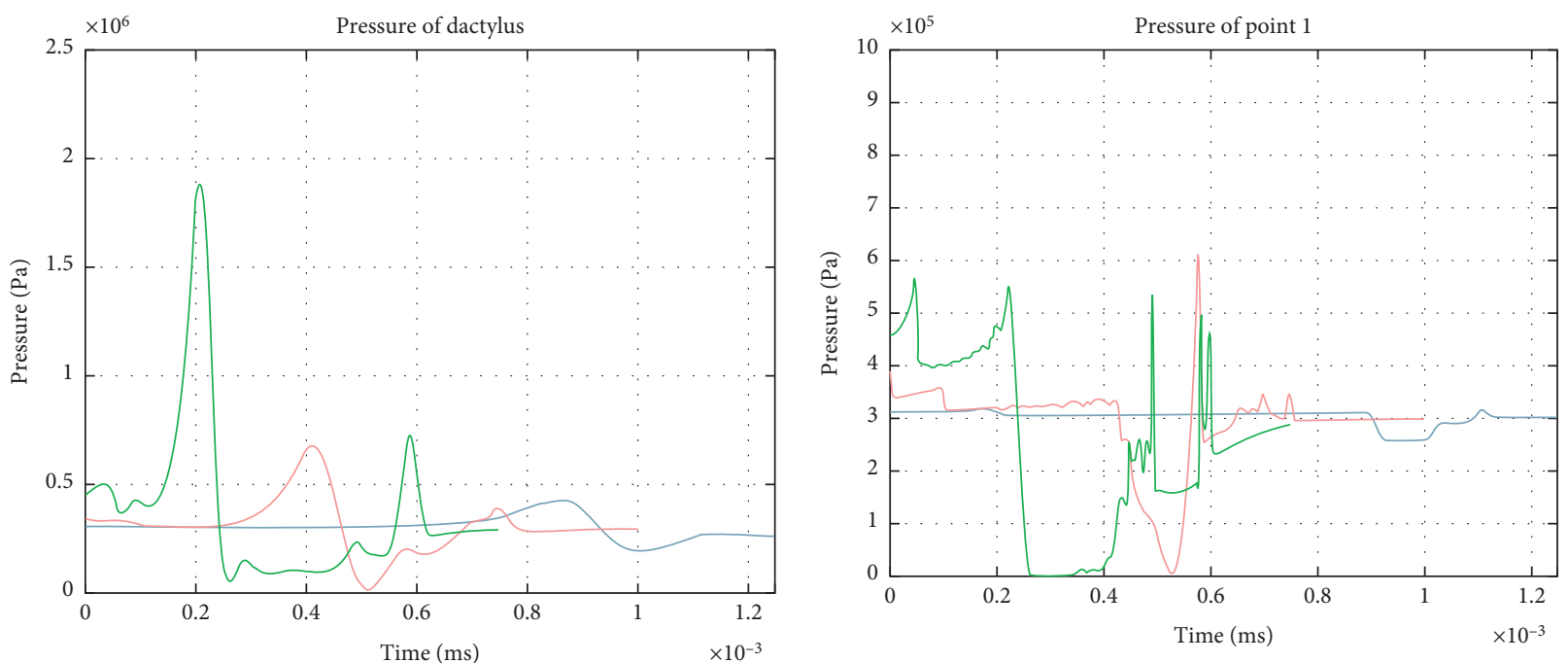

$-\mathrm{v} 1$
$-\mathrm{v} 2$
$-\mathrm{v} 3$

$-\mathrm{v} 1$
$-\mathrm{v} 2$
$-\mathrm{v} 3$

(a)

(b)

FIgURE 12: Continued. 


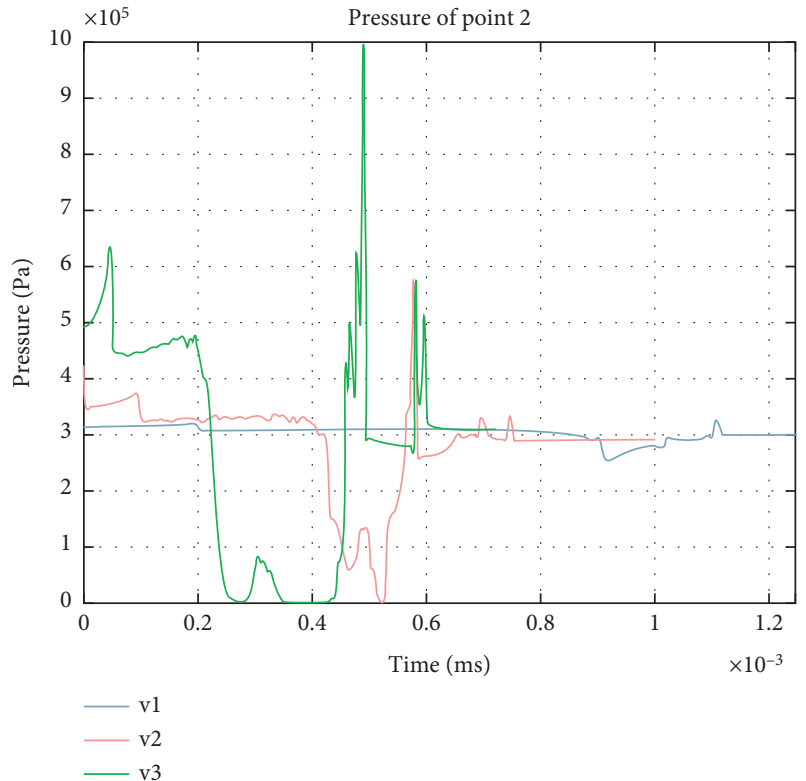

(c)

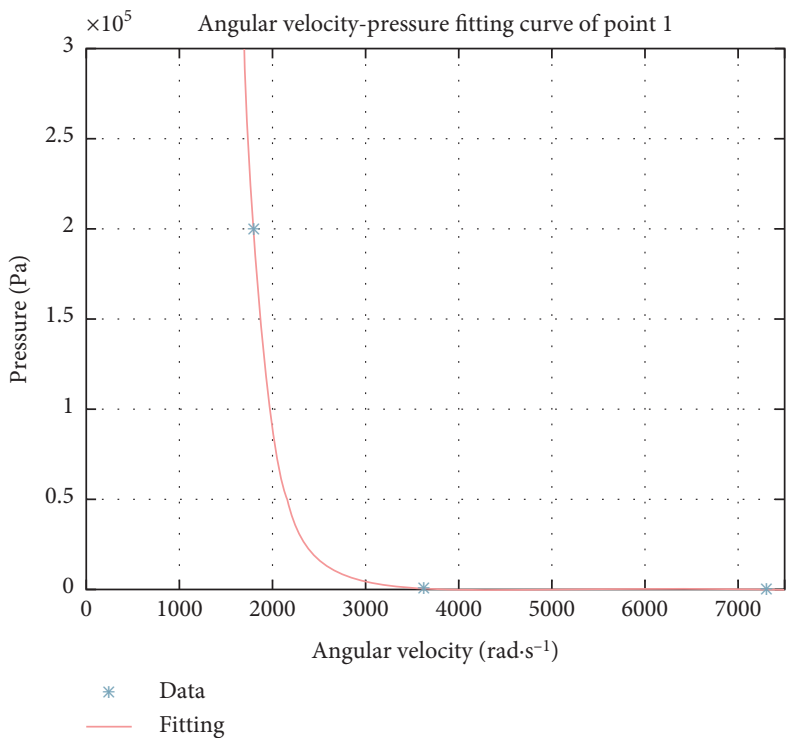

(d)

FIGURE 12: Pressure curves under different closing angular velocity. (a) Pressure of dactylus. (b) Pressure of point 1. (c) Pressure of point 2. (d) Fitting curve between the minimum of pressure of dactylus and closing angular velocity.

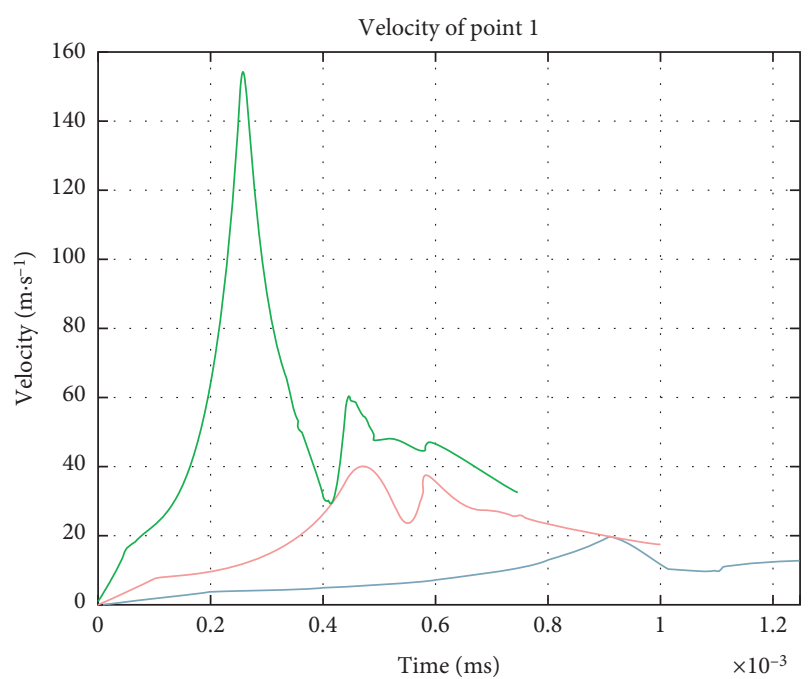

$-\mathrm{v} 1$
$-\mathrm{v} 2$
$\mathrm{v} 3$

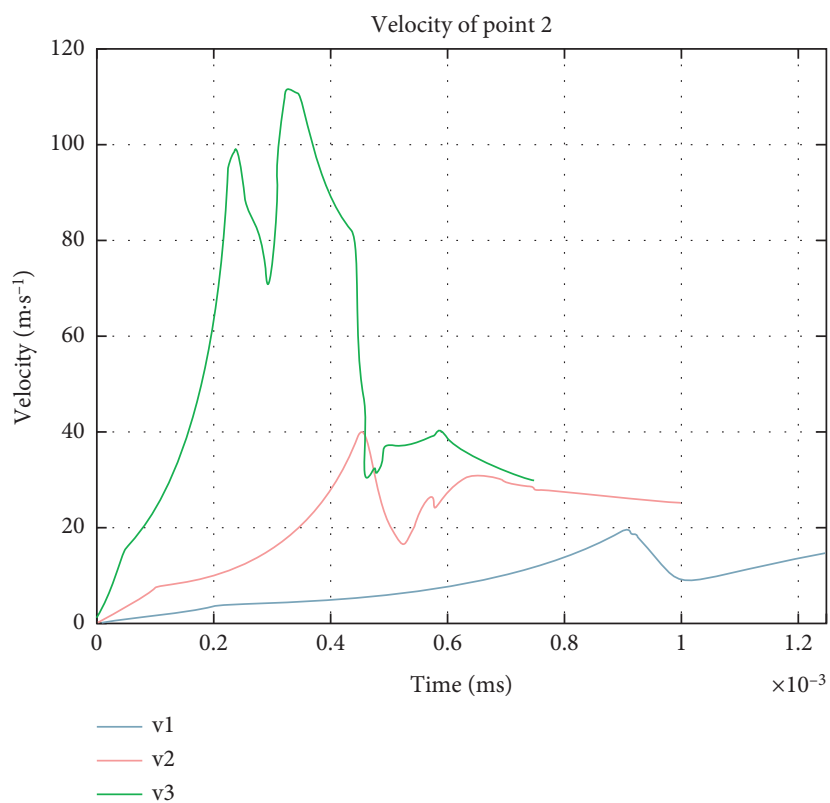

(b)

Figure 13: Continued. 


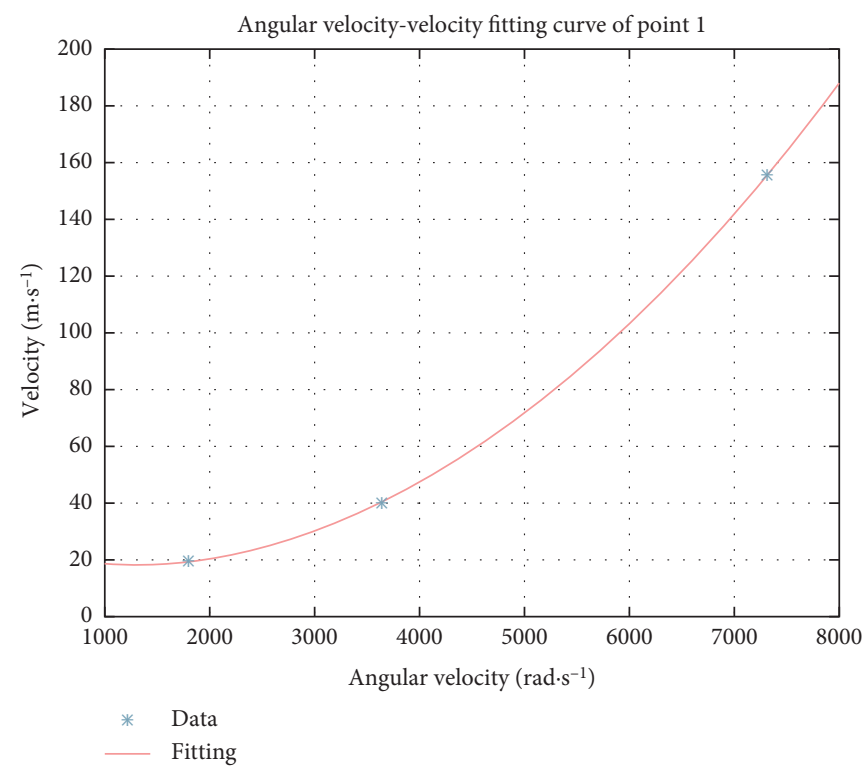

(c)

FIGURE 13: Velocity curves under different closing angular velocity. (a) Velocity of point 1. (b) Velocity of point 2. (c) Fitting curve between the velocity peak of point 1 and closing angular velocity.

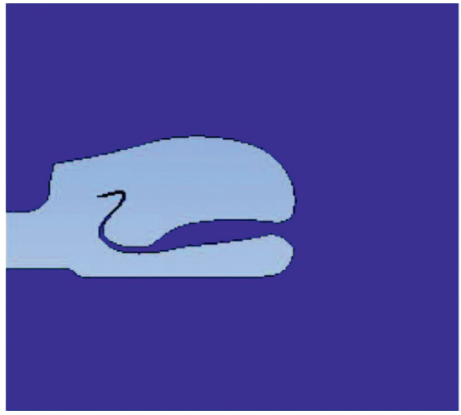

(a)

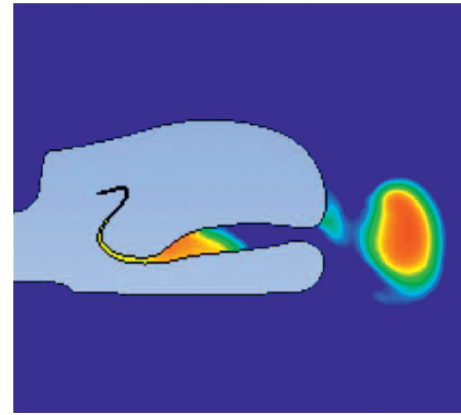

(b)

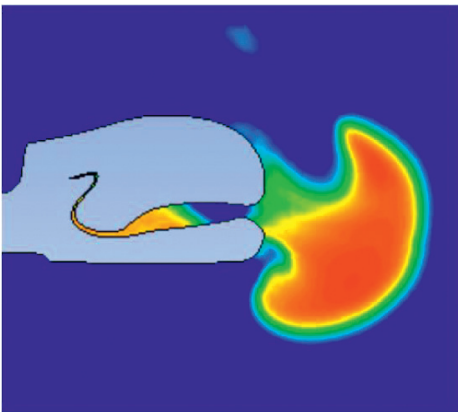

(c)

FIGURE 14: Volume of cavitation bubbles formed at different closing speeds. (a) $1810 \mathrm{rad} / \mathrm{s}$. (b) $3631 \mathrm{rad} / \mathrm{s}$. (c) $7300 \mathrm{rad} / \mathrm{s}$.

After importing the measurement data into MATLAB, as shown in Figure 18, it is the jet velocity of point 1 and point 2 with time under different closed angular accelerations. The velocity of point 1 increases again within $0.7 \sim 0.8 \mathrm{~ms}$ because the velocity of seawater fills the space instantly when the cavitation bubbles collapse. The position difference between point 1 and point 2 is $\Delta d_{12}=6.0 \mathrm{~mm}$, indicating that the velocity of the jet and cavitation bubbles moving from point 1 to point 2 is attenuated from about $55 \mathrm{~m} / \mathrm{s}$ to about $20 \mathrm{~m} / \mathrm{s}$.

As shown in Figure 19, there are three types of angular acceleration maximum bubble volume cloud images, from top to bottom, $\alpha_{1}=0.75 \times 10^{7} \mathrm{rad} / \mathrm{s}^{2}, \alpha_{2}=1 \times 10^{7} \mathrm{rad} / \mathrm{s}^{2}$, and $\alpha_{3}=1.5 \times 10^{7} \mathrm{rad} / \mathrm{s}^{2}$; the time to reach the maximum bubble is $0.67 \mathrm{~ms}, 0.63 \mathrm{~ms}$, and $0.59 \mathrm{~ms}$, respectively. It can be seen from the image that the cavitation bubble has an ellipsoidal shape, and the farthest movement distance is about $d=6.0 \mathrm{~mm}$. The section of the cavitation bubble is elliptical, with a major axis of about $5 \mathrm{~mm}$ and a minor axis of about $3 \mathrm{~mm}$. The volume of bubbles formed in the case of $\alpha_{2}$ is the smallest, and the volume of bubbles formed in the cases of $\alpha_{1}$ and $\alpha_{3}$ is approximately the same.

Figure 20 shows the bubble volume fraction curve under different closing angular accelerations. The bubble volume fraction indicates the bubble volume size. It can be seen that the bubble volume fraction of $\alpha_{1}$ reaches the maximum at $0.67 \mathrm{~ms}$, which is $92 \%$; the bubble volume fraction of $\alpha_{2}$ reaches the maximum at $0.63 \mathrm{~ms}$, which is $78 \%$; the bubble volume fraction of $\alpha_{3}$ reaches the maximum at $0.59 \mathrm{~ms}$, which is $98 \%$. It can be calculated that it takes $0.09 \mathrm{~ms}$ for the bubble to move to the farthest position in the case of $\alpha_{1}$; it takes $0.1 \mathrm{~ms}$ for the bubble to move to the farthest position in the case of $\alpha_{2}$; it takes $0.09 \mathrm{~ms}$ for the bubble to move to the farthest position in the case of $\alpha_{3}$.

The results of the study show the following: (1) The loud popping sound of the pistol shrimp is caused by the 

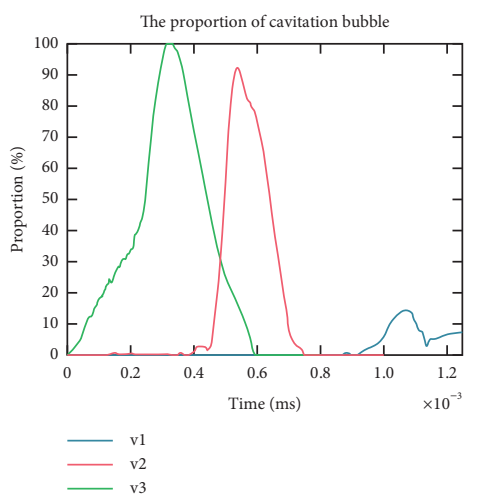

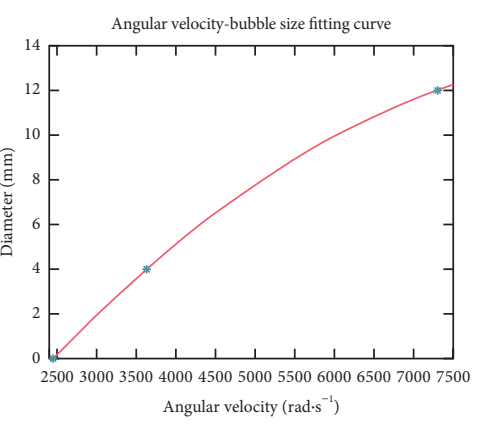

* Data

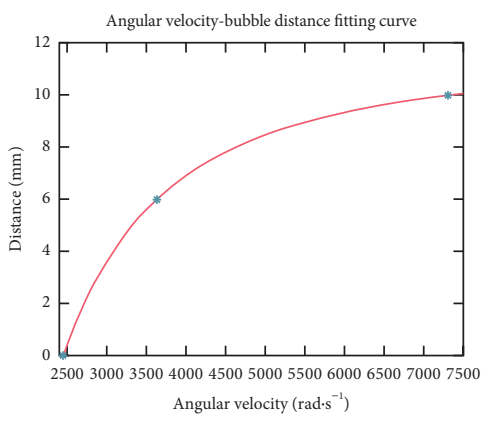

* Data

(a)

(b)

(c)

Figure 15: Curves of bubble size and bubble movement distance under different closing angular velocities. (a) Bubble volume fraction curve. (b) Fitting curve between bubble size and closing angular velocity. (c) Fitting curve between bubble distance and closing angular velocity.

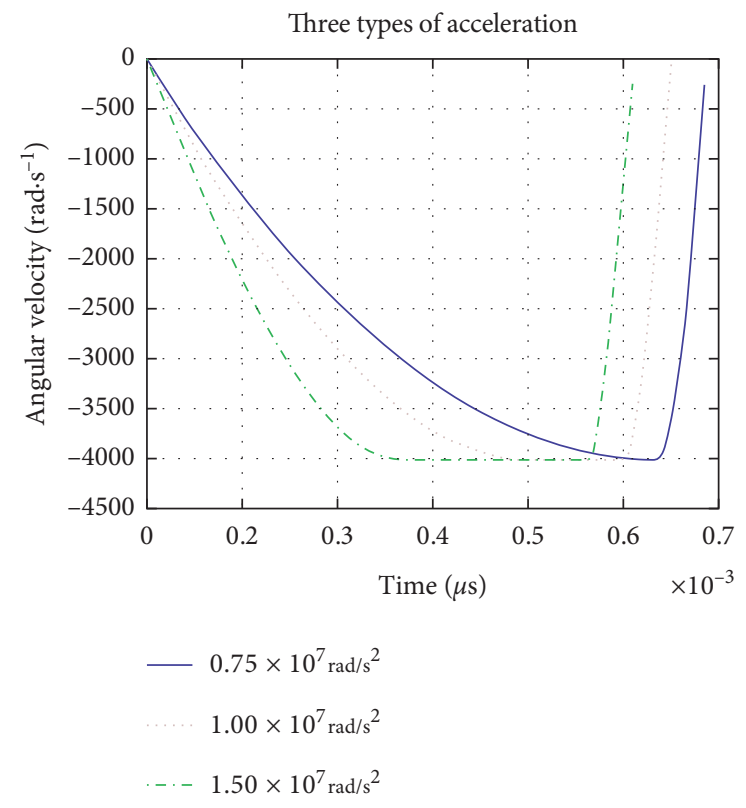

FIGURE 16: Three types of closing angular acceleration curve.

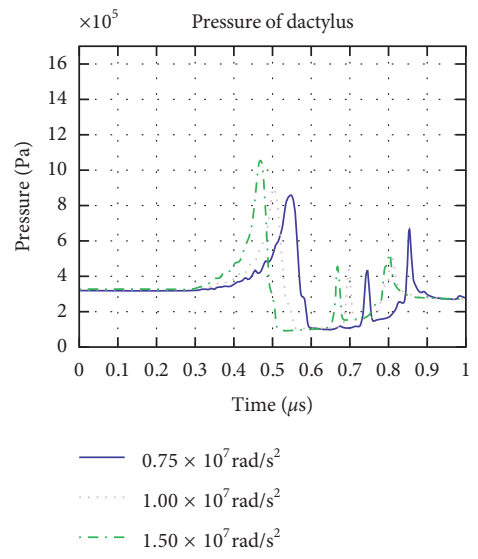

(a)

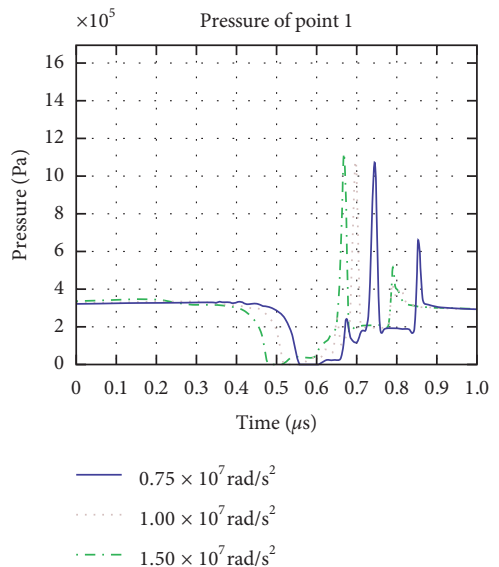

(b)

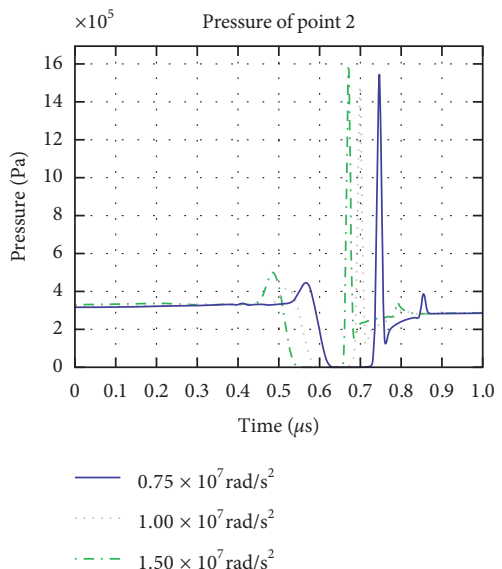

(c)

Figure 17: Pressure curves under different closing angular acceleration. (a) Pressure of dactylus. (b) Pressure of point 1. (c) Pressure of point 2 . 

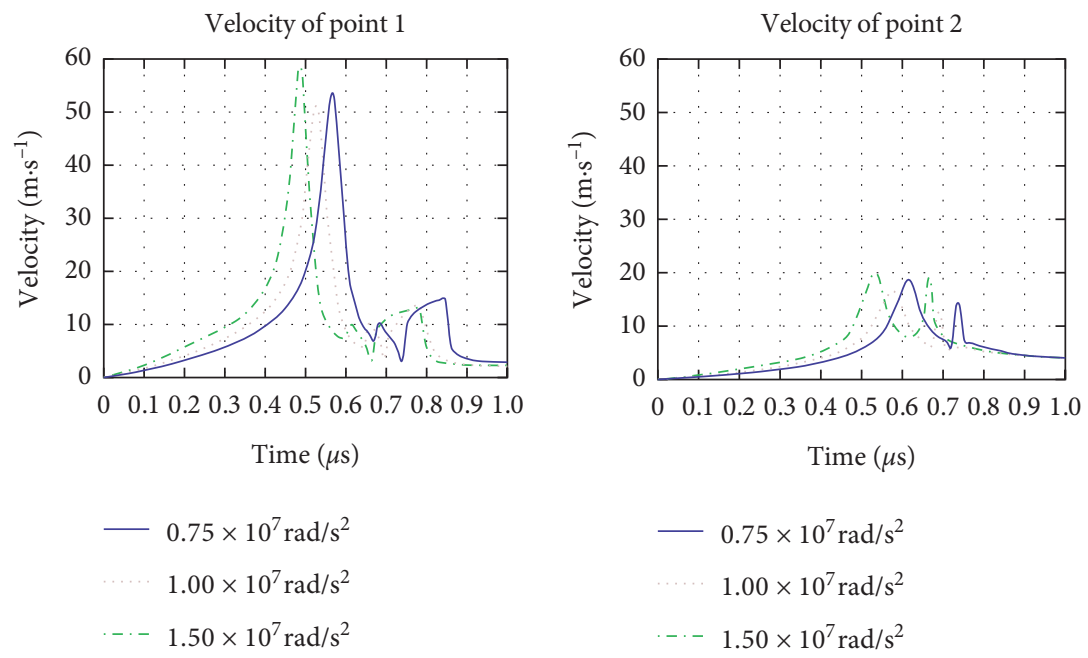

(b)

FIgURE 18: Velocity curves under different closing angular acceleration. (a) Velocity of point 1. (b) Velocity of point 2.
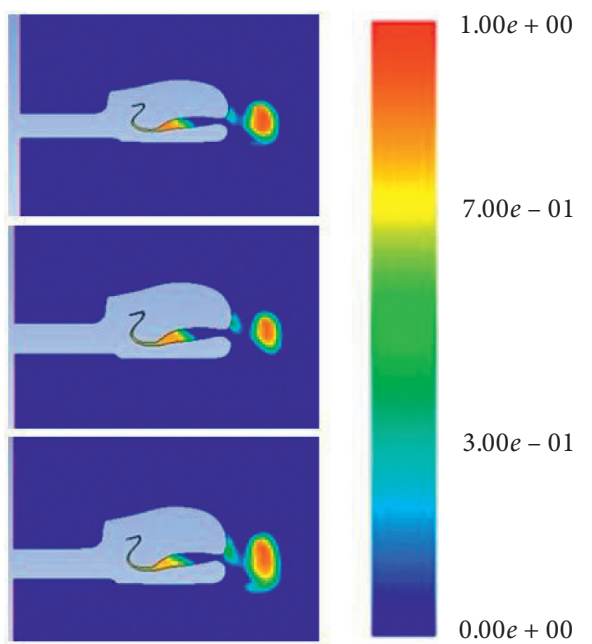

FIgURE 19: Maximum bubble volume cloud image under different closing angular accelerations.

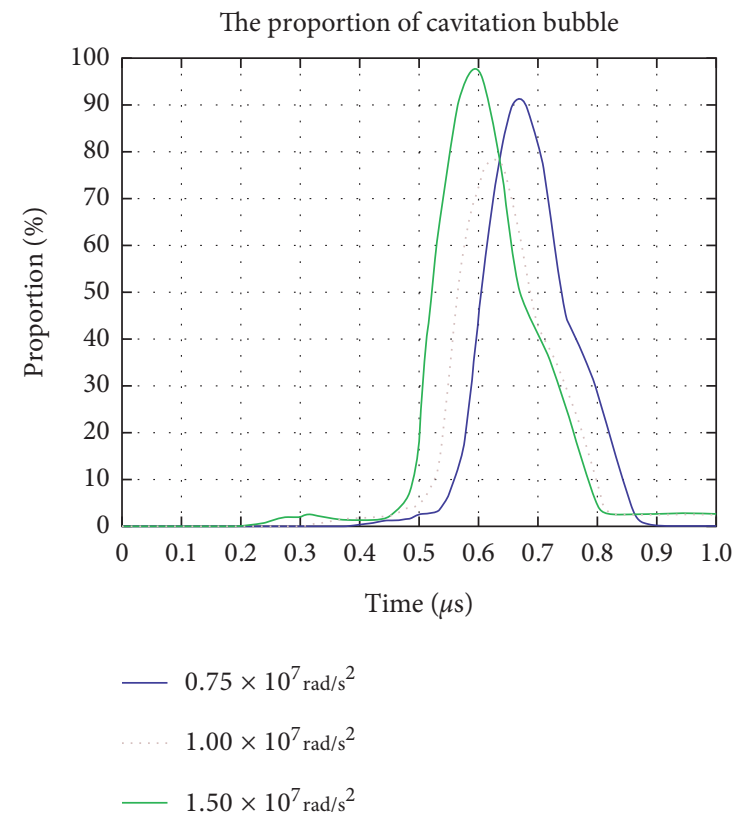

FIgURE 20: Bubble volume fraction curve under different closing angular accelerations. 
collapse of the cavitation bubbles in the high-speed water jet produced by the rapid closing of the pistol shrimp claws. (2) The pressure, velocity, bubble volume fraction, bubble movement distance, and bubble size increase with the closing angular velocity, and there is a minimum closing speed for the cavitation effect. (3) The closing angular acceleration has a very small effect on pressure, velocity, bubble volume fraction, bubble movement distance, and bubble size.

\section{Conclusions}

In this paper, firstly, a theoretical modeling of the interaction between the claws and seawater is carried out, and a cavitation model suitable for this subject is derived. Then, based on the theory of fluid-structure coupling and the physical properties of seawater, a simulation model of pistol shrimp claws and seawater was established, and the parameters were matched by combining the parameter matching reference values given by the Fluent database. Finally, taking a certain working condition as an example, the interaction process between the claws and seawater is analyzed, and the pressure, velocity, and bubble volume fraction in the closing process are obtained through the data postprocessing. The influence of different turbulence models in the simulation parameters on the simulation accuracy is analyzed, and the model that best fits the actual situation of the research content of this subject is determined. Then, using the controlled variable method, keeping the other variables the same, the effects of closing angular velocity and angular acceleration on the pressure, jet velocity, and bubble volume fraction in the closing process are studied, and the effects of closing angular velocity and angular acceleration on the pressure, jet velocity, and bubble volume fraction in the closing process are summarized. At the same time, the relationship between bubble movement distance and bubble size, closing angular velocity, and angular acceleration is studied. The mechanism of the closed jet of the claw claws is revealed, which provides a theoretical basis for the development of new underwater kinetic energy weapons.

\section{Data Availability}

The data used to support the findings of this study are included within the article.

\section{Conflicts of Interest}

The authors declare that there are no conflicts of interest regarding the publication of this paper.

\section{Acknowledgments}

This work was financially supported by the National Key R\&D program of China under Grant 2019YFB1309600, the National Natural Science Foundation of China (nos. 62073229, 51902026, and U1637207), the Self-Planned Task (no. SKLRS201801B) of State Key Laboratory of Robot Technology and System (HIT), the Qian Xuesen Laboratory of Space Technology Seed Fund (no. QXSZZJJ03-03), and the International Science and Technology Cooperation Program of China (no. 2014DFR50250).

\section{References}

[1] J. Herberholz and B. Schmitz, "Flow visualisation and high speed video analysis of water jets in the snapping shrimp ( Alpheus heterochaelis )," Journal of Comparative Physiology A: Sensory, Neural, and Behavioral Physiology, vol. 185, no. 1, pp. 41-49, 1999.

[2] M. Versluis, B. Schmitz, A. von der Heydt, and D. Lohse, "How snapping shrimp snap: through cavitating bubbles," Science, vol. 289, no. 5487, pp. 2114-2117, 2000.

[3] B. G. Ferguson and J. L. Cleary, "In situ source level and source position estimates of biological transient signals produced by snapping shrimp in an underwater environment," The Journal of the Acoustical Society of America, vol. 109, no. 6, pp. 3031-3037, 2001.

[4] B. N. Kim, J. Hahn, B. K. Choi, and B. C. Kim, "Snapping shrimp sound measured under laboratory conditions," Japanese Journal of Applied Physics, vol. 49, no. 7S, Article ID 07HG04, 2010.

[5] D. Hess, C. Brücker, F. Hegner, A. Balmert, and H. Bleckmann, "Vortex formation with a snapping shrimp claw," PLoS One, vol. 8, no. 11, Article ID e77120, 2013.

[6] B. Møhl, M. Wahlberg, P. T. Madsen, A. Heerfordt, and A. Lund, "The monopulsed nature of sperm whale clicks," The Journal of the Acoustical Society of America, vol. 114, no. 2, pp. 1143-1154, 2003.

[7] D. Lohse, B. Schmitz, and M. Versluis, "Snapping shrimp make flashing bubbles," Nature, vol. 413, no. 6855, pp. 477-478, 2001.

[8] R. E. Ritzmann, "Mechanisms for the snapping behavior of two alpheid shrimp, Alpheus californiensis and Alpheus heterochelis," Journal of Comparative Physiology ? A, vol. 95, no. 3, pp. 217-236, 1974.

[9] D. Mellon, "Nerves and the transformation of claw type in snapping shrimps," Trends in Neurosciences, vol. 4, pp. 245248, 1981.

[10] D. Mellon and P. J. Stephens, "The motor organization of claw closer muscles in snapping shrimp," Journal of Comparative Physiology, vol. 132, no. 2, pp. 109-115, 1979.

[11] J. Downer, Weird Nature: An Astonishing Exploration of Nature's Strangest Behavior, Firefly Books, Richmond Hill, Canada, 2002.

[12] M. Yuqing, L. Yanan, and Z. Shuyong, "Analysis of the physical chemistry principles of the strike process of snapping shrimp," Chemistry, vol. 7, p. 16, 2016.

[13] S. Amini, M. Tadayon, J. Q. I. Chua, and A. Miserez, "Multiscale structural design and biomechanics of the pistol shrimp snapper claw," Acta Biomaterialia, vol. 73, pp. 449-457, 2018.

[14] Z. Qian, M. Yang, L. Zhou et al., "Structure, mechanical properties and surface morphology of the snapping shrimp claw," Journal of Materials Science, vol. 53, no. 15, pp. 10666-10678, 2018.

[15] P. Alam, I. Sanka, L. P. Alam et al., "The snapping shrimp dactyl plunger: a thermomechanical damage-tolerant sandwich composite," Zoology, vol. 126, pp. 1-10, 2018.

[16] T. Kaji, A. Anker, C. S. Wirkner, and A. R. Palmer, "Parallel saltational evolution of ultrafast movements in snapping shrimp claws," Current Biology, vol. 28, no. 1, pp. 106-113, 2018. 
[17] W. B. McNamara, Y. T. Didenko, and K. S. Suslick, "Sonoluminescence temperatures during multi-bubble cavitation," Nature, vol. 401, no. 6755, pp. 772-775, 1999.

[18] A. Pereira, E. Tracey, P. C. Cooney, C. A. Korey, and M. Hughes, "Post-autotomy claw regrowth and functional recovery in the snapping shrimpAlpheus angulosus," Marine and Freshwater Behaviour and Physiology, vol. 47, no. 3, pp. 147-159, 2014.

[19] R. E. Young, J. Pearce, and C. K. Govind, "Establishment and maintenance of claw bilateral asymmetry in snapping shrimps," Journal of Experimental Zoology, vol. 269, no. 4, pp. 319-326, 1994.

[20] S. N. Patek and S. J. Longo, "Evolutionary biomechanics: the pathway to power in snapping shrimp," Current Biology, vol. 28, no. 3, pp. R115-R117, 2018.

[21] X. Wu, T. Li, J. Cai, Z. Peng, and Z. Yuan, "Numerical prediction of particle number concentration distribution in scrubbingcooling chamber of entrained-flow coal gasifier," Chemical Engineering Journal, vol. 149, no. 1-3, pp. 325-333, 2009.

[22] Z. Peng, E. Doroodchi, and B. Moghtaderi, "Heat transfer modelling in discrete element method (DEM)-based simulations of thermal processes: theory and model development," Progress in Energy and Combustion Science, vol. 79, Article ID 100847, 2020.

[23] S. V. Ghatage, M. Shakhaoath Khan, Z. Peng et al., "Settling/ rising of a foreign particle in solid-liquid fluidized beds: application of dynamic mesh technique," Chemical Engineering Science, vol. 170, pp. 139-153, 2017.

[24] A. Žnidarčič, R. Mettin, and M. Dular, "Modeling cavitation in a rapidly changing pressure field-application to a small ultrasonic horn," Ultrasonics Sonochemistry, vol. 22, pp. 482-492, 2015.

[25] F. Hong, Z. Gao, and J. Yuan, "Improved cavitation model based on Rayleigh-Plesset equation and its application (in Chinese)," Transactions of the Chinese Society of Agricultural Machinery, vol. 2, pp. 126-132, 2018.

[26] N. Koutsourakis, J. G. Bartzis, and N. C. Markatos, "Evaluation of Reynolds stress, $k-\varepsilon$ and RNG $k-\varepsilon$ turbulence models in street canyon flows using various experimental datasets," Environmental Fluid Mechanics, vol. 12, no. 4, pp. 379-403, 2012.

[27] P. Koukouvinis, C. Bruecker, and M. Gavaises, "Unveiling the physical mechanism behind pistol shrimp cavitation," Scientific Reports, vol. 7, no. 1, pp. 1-12, 2017. 